\title{
Beyond Dormancy: A Peek into the Performance of Sleep
}

\author{
Ayatree Saha
}

\begin{abstract}
Sleep as a subject of investigation might be recent, but the concept has never been alien. The association of sleep with death, and night is a Greek mythos that is also observed in the work of Shakespeare as "death's counterfeit" (Macbeth); Coleridge's account of "the pain of sleep", in the art work of Fuseli's Nightmare portraying the vulnerable and painful night. The recurrent image and account of sleep and its associated 'comatose objects' or paraphernalia, the in-between states of dreams, anxiety, fear have also created popular imaginations of how sleep is perceived. Despite the myriad forms of thoughts on sleep, it is constantly rendered to the domain of the dormant, nature, inactive, a time of quiescence which is oppositional to action, and performance of waking life. This paper delves into the performance of sleep and its associated nexus through performance art pieces, and artists, whose body is central to the way sleep is performed. The paper intends to highlight the importance of body even in states that have been construed as passive and in-action. The aim is to weave together the bodily activity of sleeping within the nexus of socio-cultural fabric. An intrinsic part of sleep is how it opens up avenue of peeking into gendered bodies through a lens that is intertwined with the social, cultural and political. The specific instance of sit-in protest against NRC (The National Register of Citizens) and CAA (Citizenship Amendment Act) in Park Circus, Kolkata is used to argue the argument of gendered and marginalized bodies occupying space and time that otherwise cannot be claimed. Sleep offers a lens to look at the performative acts of resistance that these bodies continue to posit.
\end{abstract}

Keywords: Sleep, Performance, Body, Gender.

\section{Introduction}

Sleep as a subject of investigation might be recent, but as an episteme has been there since antiquity. The association of sleep with death, and night is a Greek mythos that is also observed in the work of Shakespeare as "death's counterfeit" (Macbeth); Coleridge's account of "the pain of sleep", in the art work of Fuseli's Nightmare portraying the vulnerable and painful night. The recurrent image and account of sleep and its associated 'comatose objects' or paraphernalia, the in-between states of dreams, anxiety, fear have also created popular imaginations of how sleep is perceived. Despite the myriad forms of references, especially in poems and paintings on sleep, it is constantly rendered to the domain of the dormant, nature, inactive, a time of quiescence which is oppositional to action, and performance of waking life. The turn to sleep as a subject of inquiry opened up not only important questions of consciousness and unconsciousness, thereby the 'liminal state', but also phenomenological enquiry that took account of the very body embedded in sleeping. 
This paper delves into the performance of sleep and its associated nexus through not only performance art but also through events and accounts that draws the importance of sleeping body within the very domain of the social, cultural and political. The post-colonial texts and literature not only caused a paradigmatic shift, but brought the questions of body into prominence. This paper focuses on the subject of sleep, through a move away from 'being asleep' to 'doing sleep, as Brian Taylor (1993) proposes. With brief comments based on sleep from literature, and on dreams, in both its literal and metaphorical sense, I intend to draw the visual of the recent protest in India against NRC, CAA. In particular the focus will be on occupied spaces by women, mostly Muslim women in Park Circus of Kolkata that was in extension to solidarity with the sit-in protest at Shaheen Bagh in Delhi. The paper is based on my experience of being part of the space and time, allowing a rich description that further leads to the argument. The aim is to draw a picture of the collective vulnerabilities as well the resistance that is drawn from it, in different scenarios. Drawing from Judith Butler's Notes Toward a Performative Theory of Assembly (2015), various performance art, and of concepts and theories on sleep, I intend to tie a narrative of sleeping that is not passive (a verb nonetheless), but rather resists structures and institutions.

\section{Walking through Sleep}

I began with a basic rhythm of sleep, a move from hypnagogic state to the state of waking eyes. It is almost like a ritual; this descent is preceded by rituals and proceeded with a state of liminality where dreams offer drama, action and emotions. Dreams for some, processes healing, emotions, memories, sleep becoming mode of information, and even tool in "performance making" (Tudenham, 2016). ${ }^{1}$ But that does not imply that if there are no dreams, sleeping becomes dormant and simply asocial inaction. Sleep in itself is social, cultural as well as corporeal, but not in a sense to be only confined within medicine and sciences but rather construed through intersecting and overlapping conditions that leads to a certain kind of performance. It brings questions of time and space, pleasure and pain, labour and leisure, along with the other social underpinnings of gender, sexuality, age, race and more. Where we sleep, when we sleep, how we sleep, who we sleep with, provides the tension between the universal necessity to sleep and yet the boundaries with which the performance of sleep occurs (Taylor, 1993).

The attempt to understand sleep has been a journey, but to define it seems more interesting. From Plato, Aristotle, Kant, Freud, Derrida to Nancy, sleep has undergone epistemic changes from a 'natural' process, mode of 'relaxation', a 'life in itself', a suspension, to 'un-shareable' yet equal and common (Worthman, 2013). It is not only in literature that references to sleep have occurred, but art work and performances have provided series of images of sleep engaging with a 'suspended' realm that is beyond complete comprehension. Though study of sleep has been dominant in discipline of psychology and the emerging science of sleep medicine, performance artists have tried to explore the activity of sleep in the margins of conscious and unconscious through various modalities, which ranges from sleeping naked for long hours to using technology to map and weave the performance of sleep (Allsopp, 2016). Encouraging sleeping and engaging spectators with the act of sleeping have been parts of performances like Exit (2016), Lullaby (2011), Dream Over (2014), Dream of the Red Chamber (2014), 8 Stunden (mindestens) (At least) 8 hours) (2013), Die Ratten (2007) and many more ${ }^{2}$. These in particular either induce the audience to sleep or allow conditions of sleeping. Dreams have also been a major facet

\footnotetext{
${ }^{1}$ This was one of the most interesting read personally, as it simply narrates Tudenham's life around sleep and its ability in itself to perform the domain beyond the knowable.

${ }^{2}$ See the issue on Sleep in the Performance Research Journal 2016 for the details.
} 


\section{Beyond Dormancy: A Peek into the Performance of Sleep}

among performance artists to explore the blurring boundaries of conscious and unconscious, and the communal aspect of dream as seen in Marina Abramovic's Dream Bed (2005) and Sean Peoples and Veronica Kent's 20 Days of Dream Telepathy. Dream Bed installation lets people get into a coffin like box and lie down to fall asleep only to wake up and record their dreams. This was part of her larger project of building dream libraries in a dream house, through numerous recorded dreams ${ }^{3}$. It is fascinating how during the period of sleep in the middle of a museum everything around continues as usual. Similar experiment has also been performed by Sam Trubridge in Sleepless II (2009), only in this case he is the one who sleeps with polysomnographic equipment attached to him and an eye mask within a performance space of a gallery, with the intention to reject sleep as antithetical to performance (Trubridge, 2016). Similarly in Nightmare Inductions, where audience members are guided through nightmares of falling- losing teeth, or falling from somewhere- to make lucid sleeping a part of communal experience (Hiebert, 2016). 20 Days of Dream Telepathy is another fascinating experiment where Sean Peoples and Veronica Kent slept with 'images' beneath their pillows, to dream on it and later share it with each other the influence of the text or image on the card in their dreams (Peoples \& Kent, 2016). They later produced oil paintings based on these dreams. The intention was to see if objects that surround us, and not only something embedded within the unconscious, is capable of moulding our dreams. The attempt was to find alternative modes of communication and test the possibilities of visuals that surround, affecting dream dynamics.

The idea that I'm trying to get to and develop gradually is that of inter-dependency and communal relations that sleep can offer, despite the constructed narrative of individuality and privacy. Undoubtedly, sleeping is often very intimate and personal, but it is not devoid of social locations and corporeal inhabitation. Sleeping patterns also have a history and relies on social milieu, thereby the un-fixity and disequilibrium of it.

\section{Somnambulance and the Embodiment of Sleep}

The discourse on sleep has produced the waking world and the sleeping world. What is it that creates this binary distinction despite the acknowledgement of inter-dependency? Sleep is like a play; requires certain props, conditions or setting, role, actors, often even costumes and a period of preparation. What about the audience then? Well we can never watch ourselves sleep, what we can observe through mirror is watching how our body folds and lies in various positions. We can see the act of sleeping but not the actual 'sleep' in itself. But we have a sense of how sleeping looks or is performed, like other actions of eating or dancing or running. What is also interesting here is something that Rachel Fensham points out while analysing the dance choreography of Lucy Guerin's Heavy (1998)- the "memory of movement", of how the body needs to remember but becomes difficult as the choreography does not rely merely on meaning making but rather on varied displacements that the dancers' bodies perform (Fensham, 2016, p. 8). Like the dancing bodies in Heavy, the sleeping bodies in themselves hold meanings- the excess- that are never completely translatable and can only be surrendered to. The 'paradoxical sleep' state is the still lying body with movements induced by dynamic dream sequence within the liminal self. It is in the nothingness, the neutral, the non-meaningful that sleep becomes resilient and incommensurable to the rationality of late capitalist omnipresence of science and technology.

The contrast to this lies in the somnambulant. The somnambulant body is where

3 See https://www.pri.org/stories/2015-06-25/marina-abramovic-s-dream-bed for more on the performance. Here Sean Coles offers an insight into his experience of being part of the experiment. 
movement and sleep both meet. Sleep-walking is a form of movement that involves people walking through sleep without their knowledge. The actions performed by a somnambulant lies in the ambivalent domain, where however drastic the action might be, the entirety of it is relegated to the domain of inaction. The body however might be repository of the remains of the actions. There have been many cases of violence; sleep-violence cases where the legal repercussions of something like murder have been foregone. ${ }^{4}$

Coming back to the perception of sleep, this viewing of the act of sleeping is observable. We have seen others sleep, at home, at roads, in plays or movies or in classrooms. We have seen different postures and ways of sleeping depending on setting and the kind of people that are surrounded, which in particular points to the gendering of sleeping bodies. The very act of sleeping blurs boundary of private and public, and in itself refrains from being a 'private' thing.

The moment the word sleep pops up, visual of closed eyes and a body lying on the surface is the imagination that ensues. Even though sleep is more than that, this particular image is important and has re-occurrences within performances. Many performing artist have induced sleep or used this trope that pulls out the debate of "liveness." Early literary associations of sleep with death have found rejections through these very work that blur the boundary of life and its constructed attachment to consciousness. Dror Harari analyses the performance Insomnia (2013), where Hadas Ophrat swallowed a sleeping pill and slept amid an art festival. Harari is invested how this performance, where the actor is unconscious, vulnerable with no control within a public space is considered a 'live' art, thereby questioning the 'presence' of the artist. The performer was in the 'in-between' of every state possible. It was a choice made consciously, but the performance in itself was in a state of unconscious. The absence as well as the presence of the artist, makes Harari follow from Phillip Auslander the already mediatized nature of performance, and in this case 'liveness', that never dawns the complete presence of artist, rather is a "relative cultural-technological" concept (Harari, 2016, p. 13). Suzanne M. Jaeger however places the importance of presence that opens up the "possibility of transformation in familiar, habituated, and socially entrenched patterns through which one experiences the world" (Jaeger, 2006, p. 139). The absent-presence is still something that is performed. The $24 / 7$ access to the world outside the presence of the corporeal being, has effaced singularity of moment, and yet the presence still remains powerful as we shall see in the last section.

This raises the question of whether sleep can be 'performed'. The article also brings in mind lots of other visuals from our immediate every day. For instance the most striking thing for him is the performance being in the middle of an art festival. Public napping or sleeping in public spaces is nothing uncommon. In Japan napping in workspace, the concept of inemuri, has been predominant with the growing importance of sleep (The New York Times, 2016). This might be considered a 'diligent' act as stated by The New York Times, as it is something that most countries do not approve of, due to the loss of time. But sleeping as rejuvenation and necessary is also something that has been packaged by the capitalist mode for better productivity to the very same mode of production. Sleep is not just capitalized on but rather is served in a silver platter, to a minuscule fraction of people in the workforce, to perform better, thus putting sleep to 'work' (Baarle, 2016, p. 123). ${ }^{5}$ This also brings into play

\footnotetext{
${ }^{4}$ A. Roger Ekirch and John M. Shneerson (2011) provide instances of legal cases based on sleep violence in the nineteenth century.

${ }^{5}$ Baarle complicates the dichotomy of positive sleep- as resistance to capitalist culture and negative sleep- one that is considered useless, and argues the way something that is considered dormant and thus resistant is also used as modes of further exploitation.
} 


\section{Beyond Dormancy: A Peek into the Performance of Sleep}

the assumed vulnerability of sleeping bodies; the raised walls, locked doors and gates, not only indicate the vulnerable body, but also the risk of being robbed of material assets that are attached to the stillness of time.

We observe people napping in trains, buses, metros, a supposed private act in a public space. In a country like India, with a vast population of homeless, we come across many people sleeping on sidewalks at any point of time in the day. The way Ophrat is touched and seen by the audience, these bodies has audience who mostly unsee them (seeing yet unseeing). Both the bodies are vulnerable and can be seen among spaces that might be considered in colloquial term 'posh', these bodies mere "space invaders" (Puwar, 2004). There is an awareness of the fact that they are asleep, because of the mere way sleep descends on us and allows expression of "I'm falling asleep". The prior intention to frame a performance of sleeping on a site that is completely oppositional to that energy is what causes disruption to the whole idea of the current world based on constant movement and noise. What differs between a man sleeping on the side of Park Street in Kolkata and in middle of an art festival in Tel Aviv-Yafo in Israel, are not just their social positions (that is definitely the case), but also how one is an active resistance and the other product of the structural conditions. There should not be any comparison to the least, but what struck the author the most, is a global reality for so many. The exceptional performances against the everyday lives and reality is where the difference of performatic and performative lies. What I intended here is to point out the politics of embodiment involved in sleep that is often arbitrary and contingent, yet governed and structured.

Simon J. Williams in his sociological account of sleep illustrates the social construction of the ways of sleeping and through his historical accounts, brings forth sleep into conversation with the body. He looks at the politicization of sleep, the way in which it is disciplined and governed but yet in its excess keeps space for defiance, thereby both challenging and confirming through its "absent presence" reminding of limits to contemporary chaos (Williams, 2011). But the state of sleep is also liminal and reversible, embedded within the intersubjective world. This liminal zone is complex and vibrant with dreams, nightmares, and sleep paralysis playing their own roles. But dreams are not limited to the realm of sleep, but also come in form of public dreaming or daydreaming that transports individuals to far-off places. It's interesting how in representational modes, we see a person dreaming through bubbled vision, out of the body, at a certain distance. The body however experiences dream, through the affective connection, that leaves traces in the waking world. We might often forget the content, the image, even the premise of the dream, but what lingers, is how it made us feel. The emotions invoked by the dream, is what remains. Daydreams or lucid dreams might be shaped by the conscious self, and provide potential to be transformative, and even allow multiple performance of the self. Lucid dreams often allow exploration of personas that is limited by the body that inhabits the social world. ${ }^{6}$

Till now, I have tried to portray how various performance artists have explored the field of sleep, both beyond corporeal limits and also using bodily techniques. The performances occur in the liminal zone that is beyond complete translation and thereby remains within the body and memory. At this juncture it is also important to note that the performance of sleep, in our every day is also guided and governed by socio-cultural norms that are reiterated by us, only to often find them displaced into multitude alternatives. In this late modernity and capitalist era, as Williams points out, the policing of the night and sleep,

${ }^{6}$ See Digital Sleep and the Performance of Lucidity in Paprika (Vernon, 2016). It emphasises on the use of technology to induce lucid dreams to explore experiences that otherwise is limited. 
draws certain boundaries that are often overlooked and considered normative. The association of night with sleep, has also transformed, with coming up of industries that need people to contribute their labour throughout. Amidst all of this, a pandemic that hits globally brings a pause if not a complete halt. The 'public' and 'private' spaces have been transformed, lives affected, and sleeping patterns, cycles altered. Dreams, day or night, I suppose offers respite, flashbacks of nostalgia of the aesthetic world, along with hopes of getting lives back the way it was.

However, right before the pandemic and before the national lockdown declared in India due to the pandemic, was not a state of normal to return back to, but rather to be altered in future. Talal Asad, argues how the myth of equality that modern liberal society claims, is not of a primordial past but rather something to be aspired for, to make a better future and good political practice (Asad, 2003).

\section{The Assembly of Political Performance of Sleep}

If we have to imagine a space cohabited by a collectivity, sleeping, what is that comes to our mind? Where do we find numerous sleeping bodies? Almost sounds ghastly, but the first place that came to my mind, was the hospital. On thinking further I recollected days, when my house was filled with people during a marriage ceremony, and every nook and corner was almost filled with somebody sleeping. There are many cultures around the world that perform collective sleeping as an act of counter hegemonic signs, as seen for instance, in Maori community, during ceremonial gathering, where people sleep in their ancestral meeting-house with no particular demarcation or separation (Mejil, 2013). This is in contrast to the European practice of individuality and isolation. The cross-cultural variability of sleep with associated paraphernalia evidently rejects the singular narrative of sleep as a private act. ${ }^{7}$ The cultural embodiment of sleep shows both the constraints as well as possibilities that space and time have offered. Historically, the pre-industrial period, had bi-phasic sleep as well as the practice of sleeping in public spaces, thereby sharing the very act of sleeping. ${ }^{8}$ However, bi-phasic sleep is something that is common in West Bengal and Assam, even now. The culture of sleeping in the afternoon and at night continues to exist, where public spaces seem quieter at noon. In Guwahati especially, every shop closes by $1 \mathrm{pm}$ only to reopen at five or six in the evening. The roads bustle less, empty buses screaming for passengers and closed shutters is the image that you usually get, when out in the afternoon. ${ }^{9}$ The continued presence of this sleep activity brings into question, the constant highlight on changing patterns of sleep, putting Western history and contemporary on the pedestal, as unidirectional, universal and singular. The shift to a particular kind of space with sleep and the notion of 'privacy' and 'intimacy' that has slowly and gradually emerged is recent and Western. Not dwelling much on it, but this is only to point out the socio-cultural dimensions of sleep that vary, and provide new modes of understanding how sleep is 'performed'.

Coming to what I have been delaying till now, presence of collective sleeping bodies in a public space. The concept of public space is in itself contentious, but here, it simply is relegating to the realm of the social and political construction of 'public'. I began this section

\footnotetext{
${ }^{7}$ See Sleep Around the World: Anthropological Perspectives (Glaskin \& Chenhall, 2013), on more about the cross -cultural perspectives on sleep.

${ }^{8}$ This view has been pointed out by both Simon J. Williams in Sleep and Society (2013) and well as A Roger Ekirch in Sleep We Have Lost: Pre Industrial Slumber in British Isles (2001), and in Segmented Sleep in Pre-Industrial Societies (2016).

${ }^{9}$ This is based on my experience of two years in Guwahati, and Assam is often being referred as the land of 'lahey lahey' (laziness).
} 


\section{Beyond Dormancy: A Peek into the Performance of Sleep}

with the question of where we can observe collective bodies that sleep, and one answer to that is also protests. Globally, there have been different forms of protests- assembling and occupying- spaces to resist structures or demand justice. Historically, there have been many sit-in protests, hunger strike, Occupying Movements, each with different structures, aims, and precarity.

In December, the Citizenship Amendment Bill was placed in Lok Sabha for discussion regarding amends by granting citizenship to religious minorities from Afghanistan, Pakistan and Bangladesh who have been prosecuted. Dissent from different parts particularly Assam, began emerging, and yet the Bill was translated into an Act. However, this is in continuance with the NRC conducted in Assam that also saw resistance. The debates on migration, and the associated issues with NRC were ongoing, when the Citizenship Amendment Act hit. NRC had already instilled a sense of fear within people, especially those without documents, or with history of partition migration. Their marginal positions brought them to the forefront of being target of an exclusionary process. The CAA was based on only three countries, with people from only particular religion, excluding religious minority from other neighbouring countries as well as Muslims from the aforementioned countries. This Act was considered unconstitutional and saw active resistance which began with Assam, majorly due to their demand to not grant citizenship. Assam sharing borders with Bangladesh had a vast population of migrants residing in the state. The issue in this state was not based on religion but on ethnicity and culture, which was different from the claims that later were raised by others in various parts of the country. With voices increasing, people started pointing out the bigotry of the state and mobilizing themselves against the Act. After the incident in Jamia Milia Islamia University in Delhi, where police entered the campus and attacked students, followed by incidents in Jawaharlal Nehru University, Delhi, masses of people started mobilizing against the violence of the state apparatus. What followed was women, mostly Muslim women occupying Shaheen Bagh, began a sit-in protest that involved continued presence of large number of people day and night. Something similar also began in Park Circus in Kolkata, as an extension of solidarity to the women in Delhi as well as protest against CAA.

Resisting assemblies in any form, be it rallies, a march, or ones like this where people start living in public spaces, puts bodies at risk, for different political purposes. The bodies occupy certain spaces, whose materiality are also often transformed and are affected by the bodies. The space where these bodies inhabit, becomes conditions for emerging resistance and affect the bodies, later transforming into signifier of the protest. Butler talks about how objects, instruments that surround us, also facilitates agency, thereby the infrastructure, nature, cityscape constantly interacting with the bodies. There are varied symbolic and representative modes which play out in different spaces.

The 'voices' however are not limited to speech acts, but as Butler argues, the assembly in itself is 'voicing' or 'speaking' before the need of language to intervene. The enactment screams the collective will, even before the need for utterances. It is the plural action that plays out, with plurality of bodies performing the sense of 'We'. The bodies exercise their right and speak politically, despite precarity and the corporeal challenges. The bodies then challenge the techniques of governance through modes that often acts out spatially. The assemblies and their protest have different forms of symbols and representations; slogans, art, music, poetry, dance and more. But the bodies themselves signify something in excess than the linguistic utterances (Butler, 2015).

It is this excess that interests and concerns me here, more than what is spoken. The 
Park Circus maidan is occupied throughout, day in and night as well. I will talk about the night, the time when things are supposed to be silent, calm, quiescent yet dark, scary and deadly. Cautions against the night world are present almost in every culture, proses and poetry. This is the time we are supposed to sleep and even try to keep nightmares away. What happens when the waking world itself becomes a nightmare, from which there seems no escape, except fighting them. When lives become disposable and expendable, nights create spaces of 'lucid dreaming' to allow alternate possibilities.

The protest saw large number of people throughout the day, till midnight, speaking on microphones, eating, feeding, talking to each other, children playing. As soon as the clock ticks twelve, you see the crowd dispersing slowly. People from distant areas, who had come to shake hands, speak, extend their support, gradually go back. My first visit to Park Circus was in an afternoon, where people were singing, cheering, screaming, staring, even bonding through exchanging their every day, the way we do in families. I stayed there for some time and returned back. That is the day one of my friend told me, that we should stay at night, because the man who sells tea, told her that, they needed more people to stay at night and how early mornings go quiet. We are supposed to make 'noise'. I started wondering, what really happens the whole night. By then I had read much about events that happened in Shaheen Bagh, and images constantly kept circulating. But every image portrayed large number of people, because when there are few, who really watches? Three of us packed a bag each and reached there after ten at night.

The area was filled with men and a circular boundary was created inside which women were sitting. The place is built around an elevated platform, which is the only area which was sheltered; the rest of the place was an open space. This is in January, one of the coldest months, and for a place like Kolkata where streets went quite by ten, this place was vibrant. Everyone was smiling, filled with energy. There were also moments of silence. The plural bodies involved in multiple actions, filled with silence, allowing their 'corporeal' presence to speak. After midnight the circle narrowed, it got closer, and after some time, it was limited to all women being seated inside the platform. Some were outside roaming, having tea; the fruit shops were open for a long time. Time almost seemed to stopped. We started witnessing sleepy faces and sleeping bodies. After walking down the street, having oranges (because they were beautiful), and tea from a boy from Mumbai, we kept ourselves awake through conversations about the precarity of people's lives, the state in which the nation is and more. By three, there was a sudden tranquility. A man started playing his flute, another man narrated stories about his childhood, and women lay asleep on sheets shifting in their blankets. These bodies are not merely performative of the present, but rather have histories, and in dialogue with preceding historical positions of power. "As woman, she is preceded by her own markings, standing in relation to her body in history as if beside herself" (Schneider, 1996), and here lies not only the history of gender but also the intersecting identity of religion, thereby the body coded with historical markings.

It is at moments like these, when you realize your gendered body more than ever. Being in spaces that is not meant for us, at a time that increases our vulnerability, yet occupying that space with diverse gendered bodies, gave a sense of comfort and power. Occupying a space that systematically excludes us is in itself political and resilient. Saba Zaveri narrates her performance of choosing any particular spot in Tehran, spreading a sheet to create 'her' space amidst the boundary of public and private, with a pillow and duvet in her arms, going off to sleep (Zaveri, 2016). Her feminine body, conscious of the gaze on a woman with clean clothes and tidy 'skin', transgresses the boundaries that limited her dreams and hopes. The 'inappropriate' occupying of a space, haunts the 'outsider', who sees the 


\section{Beyond Dormancy: A Peek into the Performance of Sleep}

'interior' and 'domestic' conflicting the collage of ideological norms. She however continues her performance of hopes, and dreams in the space as if a "big communal bedroom" with "guardians of sleep" (Zaveri, 2016, p. 80).

My 'presence' at Park Circus, lived multiple, singular moments, and I say so because with the rising dawn, emotions set in eerily. It was like watching something beautiful. The silence was filled with the remains of the music, the debates, and the demands of 'Azaadi'. The echoing voices were not quite audible, but could be felt, especially with the backdrop of flute. What was left of the night, a few wide eyes and the lying bodies asleep in rows. These bodies are gendered and vulnerable bodies, but with this vulnerability come their agency. The stillness that dawned the space continued mobilizing vulnerabilities in concert, as Butler puts it. Nothing stopped, not the protest, not the night, nor the voices. The stillness continued to perform itself in that liminal state. Sleeping was no more mere passive, it made statementsthe statement of presence, the statement of reclaiming spaces, the statements of precarity, and histories of violence that the bodies embodied. The darkness of the night continued to be creative, allowed these women to dream; dream of a future that their resistance might pave for them. The act of sleeping might still be considered passive, but the body that sleeps is actively resisting; the collective presence, was a plural performative action under conditions of precarity.

This is not devoid of the affective dimension that the space embodies and continues to do so with practices that disallows the emotional energy to dwindle, rather co-produce emotional charge and social meanings. There is a constant exchange of emotions within the resistance that mediates relationship between an individual and the collective (Ahmed, 2004). The collective that inhabits the space is one that is transient. People from different religion, gender, class, caste, and ethnicity interact within the space. The way Susan Leigh Foster illuminates on "kinesthetic empathy" (Foster, 2007, p. 246) foregrounding on dance performance, the performance in the protest is also aligned by emotion between the bodies those move or do not.

I was part of the space, the emotions, the bodies, the objects, and the performance. Erika Fischer-Lichte (2008) points out the transformative power of performance and so does Saba Mahmood (2005) through her ethnography, the way artists and art or performance interact and transform each other. The performance of the night is what was transformative for me. I was neither an ethnographer, nor a spectator, nor an artist; rather simply a gendered body (or maybe all of them) whose presence was a minuscule part of a movement. As the light hit the streets, and we could hear the local train whistling off, smell of fresh tea exuding the air, people opening their eyes to witness themselves still surrounded by familiar and unfamiliar faces. The aesthetic and the political kindle, the performative acts producing political effects (Fuentes, 2015). In wrestling power, a new in-between is created that reclaims, re-configures spaces through bodily alliances (Butler, 2015, p. 85).

\section{Conclusion}

Aristotelian idea of women being incapable of the political, the very idea on which citizenship was based, thus women having no voting rights for the longest time, is challenged. The corporeality of women and slaves were reduced to mere facticity, disposable and perishable. The paper draws out specific instances of performance of sleep. It can be set against the everyday, which is yet to be explored. The form of protest in Park Circus, Kolkata or Shaheen Bagh, Delhi, showcased how the body in itself is political. It is not 'as if' the role of protestor is performed, or a text being iterated, or framed within particular time. The 
bodies speak of their vulnerability, vulnerability of not only bodily injuries, but also that of the unknowable (Butler, 2015). My visits to Park Circus gave a sense of their repertoire of everyday performance. Sleep which is considered so dormant, inactive and fixed was also political. The entire time, there is sloganeering, singing, poetry and various other performances. As the night descended, children and women fed, it felt more like a space resonating home. Women started sleeping, crowd fading, only few having everyday conversation, someone playing the flute. These behavioural configurations and reclaiming space stem from expansion of repertoire of protest (Fuentes, 2015). The act of sleeping posed a continuity of performance of resistance by reclaiming a space that did not end with active engagement by 'wakefulness'. The "remains" of the performance resides in the memory, in the flesh, that disallows complete arrest, and translatability (Schneider, Performance Remains, 2012). The liminal state of performing sleep remains contingent and unstable, even not completely tameable, but does not disappear (Phelan, 1993), rather remains in ways that are incommensurable to the archive.

The paper tried to weave together a loom, through pieces from performances, art work, protest, images, visuals, literary expressions, that would form a blanket that portrayed the nexus of sleep- night, dreams, nightmares, daydreams- performing the liminal. In a 24/7 world of fleeting moments and liquid temporality, with atrophied communal experiences, this paper tried to perform the ways bodies- sleeping bodies- despite being governed through socio-cultural and even economic and political milieu, can offer communal experiences that refute the acceptance of stability and certainty. It however does not intend to pull nostalgia of a past, but rather illustrate a present that is fractured yet resisting through liminal states in varied kind of performances, including performance art. The earlier association of sleep with death is like how during all the above mentioned performances of sleeping either at gallery space or within art festival, there was no discord in the continuance of surrounding. However, this absent-presence is an interlude of renewal, indication of a future life not yet lived, of freedom and anticipation of a beyond that is unknown and counter-deathly. ${ }^{10}$

\section{References}

Ahmed, S. (2004). Affective Economies. Social Text 117-139.

Allsopp, R. (2016). On Sleep. Performance Research 21(1), 1-5.

Asad, T. (2003). Formations of the Secular. Stanford, California: Stanford University Press.

Baarle, K. V. (2016). Kris Vendrock's EXIT. Performance Research 21(1), 120-125.

Butler, J. (2015). Notes Toward a Performative Theory of Assembly. Harvard University Press.

Ekirch, A., \& Shneerson, J. M. (2011). Nineteenth-century sleep violence cases: a historical view. Sleep Medicine 6(4), 483-491.

Ekrich, A. R. (2001). Sleep We Have Lost: Pre-Industrial Slumber in British Isles. American Historical Review 106(2), 343-386.

Ekrich, A. R. (2016). Segmented Sleep in Preindustrial Societies. Sleep 39(3), 715-716. doi:https://doi.org/10.5665/sleep.5558

Fensham, R. (2016). Heavy- Sleep, Dance, Loss. Performance Research 21(1), 6-11.

\footnotetext{
${ }^{10}$ I have not spoken of insomnia even though it is an intrinsic aspect. The reason is not because, insomnia is related to not being able to sleep, but because, insomnia and the idea of 'insomniac genius' along with the modern late capitalist nexus is in itself a whole line of enquiry.
} 


\section{Beyond Dormancy: A Peek into the Performance of Sleep}

Fischer-Lichte, E. (2008). The Transformative Power of Performance. In The Transformative Power of Performance: A New Aesthetics (pp. 11-23). Routledge.

Foster, S. L. (2007). Kinaestheic Empathies and The Politics of Compassion. In J. Reinelt, \& J. Roach (Eds.), Critical Theory and Performance (pp. 245-257). Ann Arbor: University of Michigan Press.

Fuentes, M. A. (2015). Performance, politics, and protest. Duke university Press. Retrieved from http://scalar.usc.edu/nehvectors/wips/performance-politics-and-protest

Glaskin, K., \& Chenhall, R. (Eds.), (2013). Sleep Around the World: Anthropological Perspectives. Palgrave Macmillan.

Harari, D. (2016). Is the Artist Present? Performance Research 21(1), 12-17.

Hiebert, T. (2016). Lucid Sleeping. Performance Research 21(1), 31-36.

Jaeger, S. M. (2006). Embodiment and Presence. In D. Krasner, D. Z. Saltz, D. Krasner, \& D.Z. Saltz (Eds.), Staging Philosophy: Intersections of Theatre, Performance and Philosophy (pp. 122-141). University of Michigan Press.

Mahmood, S. (2005). Politics of Piety. Princeton University Press.

Mejil, T. v. (2013). Maori Collective Sleeping as Cultural Resistance. In K. Glaskin, \& R. Chenhall (Eds.), Sleep Around the World (pp. 133-150). Palgrave Macmillan.

Peoples, S., \& Kent, V. (2016). 20 Days of Dream Telepathy. Performance Research 21(1), 53-57.

Phelan, P. (1993). The Ontology of Performance: Representation without Reproduction. In P. Phelan, Unmarked: The Politics of Performance (pp. 145-166). Routledge.

Puwar, N. (2004). Space Invaders- Race, Gender and Bodies Out of Place. New York: Berg.

Rousseau, B. (2016, December 16). Napping in Public? In Japan That's a sign of Diligence. The New York Times.

Schneider, R. (1996). After Us the Savage Goddess: Feminist Performance Art. In E. Diamond (Ed.), Performance and Cultural Politics (pp. 157-178). Routledge.

Schneider, R. (2012). Performance Remains. In A. Jones, A. Heathfield, A. Jones, \& A. Heathfield (Eds.), Perform, Repeat, Record: Live Art in History (pp. 137-150). Intellect Press.

Taylor, B. (1993). Unconsciousness and society: The sociology of sleep. International Journal of Politics, Culture, and Society 6(3), 463-471.

Trubridge, S. (2016). Dream Analysis. Performance Research 21(1), 72-78.

Tudenham, J. L. (2016). Best Residency Programme, Open to All: Sleep. Performance Research 138-139.

Vernon, A. (2016). Digital Sleep and the Performance of Lucidity in Paprika. Performance Research 21(1), 115-119.

Williams, S. J. (2011). The Politics of Sleep: Governing (Un) Conscious in the Late Modern Age. Palgrave Macmillan.

Williams, S. J. (2013). Sleep and Society: Sociological ventures into the (un) known. Routledge.

Worthman, S. M. (2013). The Poetics of Sleep. Bloomsbury.

Zaveri, S. (2016). Sleeping with Tehran. Performance Research 21(1), 79-82.

\section{Bio-note}

Ayatree Saha is currently pursuing M.Phil from Centre for Studies in Social Sciences, Kolkata. She has graduated from St. Xavier's, Kolkata with Sociology honours and completed her post-graduation in Sociology and Social Anthropology from Tata Institute of Social Sciences, Guwahati. Being sociology major, her interest area lies in sociology of sleep, gender, culture with specific focus on the importance of the body. Having worked on 
menstrual rituals in Assam, as part of her Master's thesis, the body as a subject of investigation is crucial to her research. Currently she is working within an interdisciplinary paradigm to explore more of the subject of sleep.

Email Id: ayatreesaha.30@gmail.com 